\title{
La geometría constructiva del Cimborrio de la catedral de San José de Cúcuta
}

\section{The constructive geometry of the dome of cathedral of San José de Cúcuta}

\author{
Yannette Díaz Umaña ${ }^{1}$ \\ Julio Alfredo Delgado Rojas ${ }^{2}$ \\ Mawency Vergel Ortega ${ }^{3}$ \\ Universidad Francisco de Paula Santander.
}

\section{RESUMEN}

El objetivo principal del escrito basado en la investigación en arquitectura sagrada, desarrollado de forma integral por el programa de arquitectura y el departamento de matemáticas de la UFPS, mediante un estudio de tipo descriptivo, tiene como propósito establecer las características simbólicas, arquitectónicas y geométricas del cimborrio de la Catedral de San José de Cúcuta. Se tiene en cuenta del mismo modo, el estudio documental, comparando los

1 Magister en Gestión Urbana, Arquitecta, docente y directora del Departamento de Arquitectura, diseño y Urbanismo. Filiación: Universidad Francisco de Paula Santander. Correo electrónico: yannettedu@ufps.edu.co Orcid: https://orcid.org/0000-0003-4582-1593

2 Magister en Educación Matemática, Arquitecto, Docente. Filiación: Universidad Francisco de Paula Santander. Correo electrónico: julioalfredo@ufps.edu.co Orcid: https://orcid.org/0000-0001-6944-832X

3 Doctora en Educación. Postdoctora en Imaginarios y representaciones sociales. Docente y Directora del Departamento de Matemáticas y Estadística. Filiación: Universidad Francisco de Paula Santander. Correo electrónico: mawency@ufps.edu.co. Orcid: https://orcid.org/0000-00018285-2968 datos obtenidos en sitio con las características propias de la arquitectura de la Catedral, y de esta manera lograr la comprensión del fenómeno estudiado.

PALABRAS ClAVE: Cimborrio, Cúpula, técnica constructiva, arquitectura, simbolismo.

\section{ABSTRACT:}

The main objective of the writing based on the research of sacred architecture, developed in an integral way by the program of architecture and the department of mathematics of the UFPS, through a study of descriptive type. One of the purposes was to establish the symbolic, architectural and geometric characteristics of the dome of San José de Cúcuta Cathedral. In the same way, the documentary study is taken into account in an orderly way, comparing the data obtained on site with the characteristics of the architecture of the Cathedral, and in this 
way achieving the understanding of the studied phenomenon.

KEYWORDS: Dome, Dome, construction technique, architecture, symbolism

\section{INTRODUCCIÓN}

Para empezar, "La geometría constructiva del cimborrio de la catedral de San José de Cúcuta.", está referido a la construcción más emblemática de la Iglesia católica de esta ciudad, según Delgado Diaz, \& Vergel (2018). Uno de los elementos más icónicos de la catedral, es su cimborrio, definido por cuerpo saliente al exterior, generalmente de planta cuadrada, que se levanta sobre el crucero de la catedral para iluminar su interior. El desarrollo del cimborrio se hace a través de su cuerpo cilíndrico (el tambor) que sirve de base a la cúpula y que descansa sobre los arcos torales. Hacia el exterior este cuerpo resalta sobre el paisaje urbano con su forma poco convencional, de tal manera que se podría afirmar su papel en la sacralización de la ciudad por intermedio de este símbolo. Al interior despliega toda su perfección espacial y fenomenológica con la que logra ser un punto articulador de toda la construcción. De igual forma, la copula configura un skyline curvilíneo atípico, pues se contrapone a las superficies rectilíneas de los perfiles constructivos que predominan en la ciudad. Especialmente en la actualidad, donde adquiere por contraste una enérgica volumetría. En este sentido Baeza (2014) comenta el valor histórico y cultural de la cúpula, debido a múltiples razones, por ejemplo, su ingenio al procurar la sensación de ingravidez y por sus orígenes multiculturales por lo que expresa una total admiración por las cúpulas de las mezquitas bizantinas, la majestuosa cúpula que hizo Miguel Ángel para la basílica de San Pedro de Roma, y por supuesto la cúpula de la catedral Toscana con la que Bruneleschi sorprendiera a la humanidad. (Figura 1)

Figura 1. Cuadro comparativo de la sección de la cúpula de la Catedral de San José de Cúcuta, con las de Santa María del Fiore y Basílica de San Pedro.

\begin{tabular}{|l|l|l|}
\hline $\begin{array}{l}\text { SANTA MARÍA DEL FIORE } \\
\text { Filippo Brunelleschi }\end{array}$ & $\begin{array}{l}\text { BASÍLICA DE SAN PEDRO. } \\
\text { Miguel Angel Buonarroti }\end{array}$ & $\begin{array}{l}\text { CATEDRAL DE } \\
\text { SAN JOSE DE CÚCUTA. } \\
\text { Desconocido }\end{array}$ \\
\hline & &
\end{tabular}

Fuente: Propia según imágenes de Google Nat geo y levantamiento propio de cúpula. 


\section{ANÁLISIS Y DISCUSIÓN}

El valor simbólico, que Baeza (2014) le confiere, al cimborrio por dotar al edificio de un carácter sagrado vinculando su significado cosmológico al representar en su remate la "bóveda celeste". Algo semejante ocurre con Llonch \& Gurrea (1996) cuando relacionan el poder simbólico de la cúpula, por su posible origen, relacionando varias culturas como los caldeos y asirios, persas sasánidas, romanos y bizantinos en sus inicios, así que deja abierta la posibilidad a una hipótesis que establece su comienzo en Oriente o en Occidente, dejando claro, que ante la imposibilidad de dar tal precisión sobre su comienzo, lo importante es destacar, que la transmisión de la técnica constructiva de la cúpula, alcanzó una alta calidad arquitectónica, precisamente por la participación multicultural y su adquisición paulatina y transmitida a lo largo del tiempo aplicada a las diferentes técnicas de ejecución.

Estas apreciaciones son pertinentes como preámbulo a las condiciones particulares del cimborrio de la Catedral de San José de Cúcuta, apoyado en las pechinas que, a su vez, se afirman sobre los arcos torales, dispuestos en una base cuadrada delineada por el crucero. En la cúpula se destaca su extradós semiesférico revestido con hojas traslapadas en concreto. Esta solución constructiva permite compatibilizar la geometría de la cúpula con las nervaduras integradas. Sobre ella, se encuentra la linterna conformada por ocho vanos enmarcados por pilastras de fuste liso, en su parte superior se ubica un capulín, de características similares a la cúpula, pero en menores proporciones, finalmente el remate es logrado en la parte más alta, con la bola y la cruz a una altura de $35 \mathrm{~m}$ sobre el nivel del suelo. Para Rivas (2008) la cúpula constituye un elemento protagónico por su elevada posición y su remate compositivo de toda la edificación.
En otro sentido, la atención lograda por la cúpula, en la arquitectura Sagrada, sobrepasa su premisa compositiva, definida por la intersección de la nave central y el transepto, a una altura aproximada de $23 \mathrm{~m}$ sobre el altar. Esta practica estilística se ve relacionada con la intensión litúrgica, ya que ambas tienen como punto de referencia el altar. Esta ubicación de la zona presbiteral, en el centro de la iglesia, fue motivada por las reformas preconciliares cuya intención era la participación de los fieles en la liturgia, tal como lo narra (Díaz 2019), tras una ubicación más alejada en el ábside, como era la práctica antigua y medieval.

Por su parte Rosenthal (2011), haciendo alusión a esta circunstancia, habla de la democratización, de la redención de la intimidad de la celebración de la misa paleocristiana, y de estar unidos en torno al altar, en el centro cupuliforme de la iglesia. Este mismo autor subraya que los ejemplos de esta disposición espacial del altar centralizado bajo la cúpula, se ven singularmente en esquemas de forma de cruz latina, tal como se evidencia en la Catedral. Debido a estas concepciones es prudente afirmar que la cúpula trasciende en su papel estético de criterios meramente ornamentales para seguir pautas fundadas en el simbolismo.

Con esta configuración, interiormente se dispone un espacio fenomenológico, en donde la cúpula como centro de la catedral, esta sostenida por los cuatro arcos torales, esta estructura permite que la cúpula parezca estar suspendida en el aire, apoyando la sensación de ingravidez y representando el mismo cielo. No obstante, la disposición espacial interna del crucero, va más allá, al revelar una jerarquía ascendente que insiste en revelar su valor simbólico. (Figura 3) 
Figura 3. Vista en axonometría de la Catedral de San José de Cúcuta. Y vista planta general.
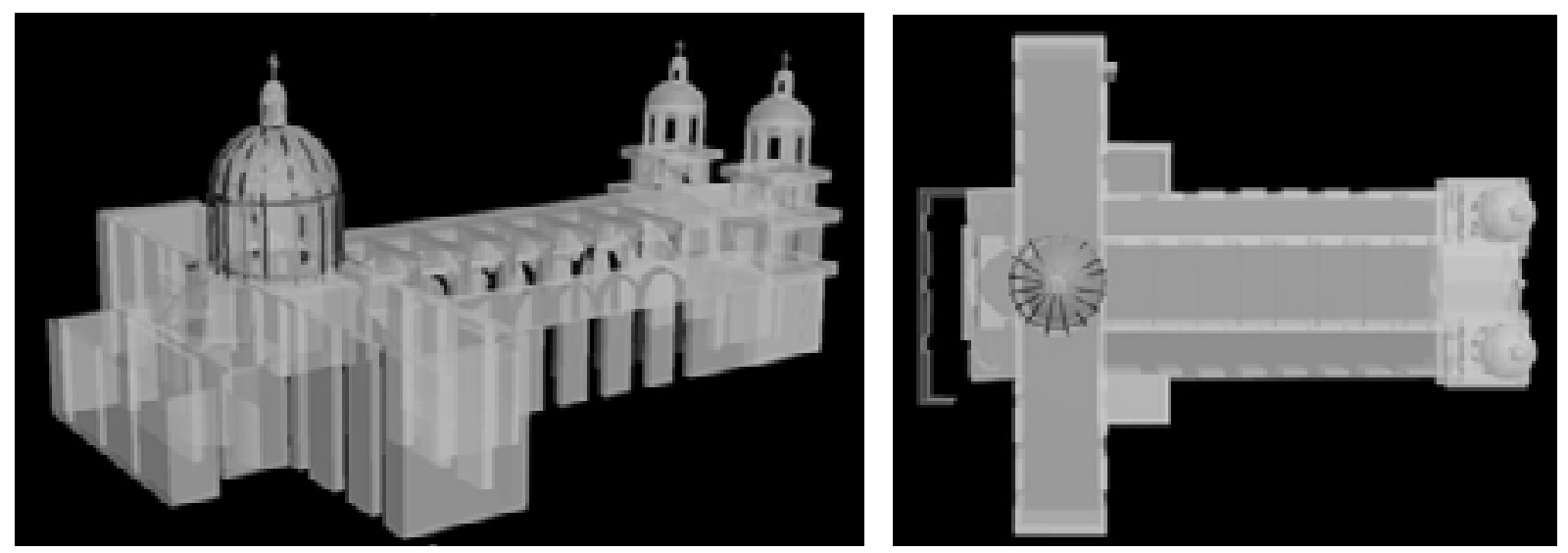

Fuente: Catherine Contreras.

En efecto, las pechinas que descansan sobre los arcos torales, las cuales hacen alegoría cada una de ellas a la tradición, el evangelio, la Santa Madre de Dios y la Eucaristía, como base de la iglesia católica. En segunda medida, un conjunto de santos, mártires y ángeles, representados en sus ocho vitrales que rodean tambor con 6.67 $\mathrm{m}$ de alto. Y la última jerarquía, que acentúa su valor fenomenológico, por cuanto la impresión visual es estimulada por la ornamentación pictórica del intradós de la cúpula, desarrollada en un espacio de $9.80 \mathrm{~m}$ de diámetro por una alzada de $6.08 \mathrm{~m}$ recreando al Padre Celestial, Jesús, San Pedro, y los serafines, en el cielo

De esta manera la jerarquización ascendente presenta de alguna manera alegóricamente el camino a la salvación. Ahora bien, el arte plasmado en la estructura de la cúpula, cumple su papel pedagógico y didáctico, al que se complementa de forma magistral el juego de la luz, pues al penetrar por el óculo y los vitrales del tambor, en las diferentes horas del día, se entre cruzan los haces lumínicos, a diferentes alturas revelando sobre las superficies internas, la incidencia del sol. Para Marín (2001), haciendo referencia a la cúpula de catedral de Edessa describe el efecto fenomenológico en el fiel, al sobrecogerse por la iluminación y deslumbrado por la luz, material y mística, que irradia la cúpula.
En cuanto la descripción constructiva de la cúpula, se puede determinar que su soltura geométrica se desprende de su centro con 16 nervaduras radiales que configuran su trazado circular, para Aliberti (2013) las cúpulas tienen generalmente una abertura cenital $u$ óculo con fines lumínicos y constructivos ya que facilitan el cierre de la estructura. Esta abertura se encuentra generalmente en una proporción que oscila entre $1 / 4$ y $1 / 6$ (Aliberti 2013). Estas observaciones se relacionan con los $9.80 \mathrm{~m}$ de diámetro de la planta, la altura de $6.08 \mathrm{~m}$, precisa una proporción de 1/16. En este aspecto Aliberti (2013) y Huerta (2004) indican que, aunque el espesor de las cupulas es variado la relación existente con su diámetro oscila entre $1 / 9$ y $1 / 42$, siendo en la mayoría de los casos entre $1 / 16$ y $1 / 22$ con una media general de 1/20.

En cuanto a la manufactura de ladrillo de la cúpula, supone entre 40 y $50 \mathrm{Kg} / \mathrm{cm} 2$ de resistencia a la compresión y entre 2 y $5 \mathrm{KG} /$ cm2 de resistencia a la tracción. Con estas aproximaciones Martínez \& Alonso (2003), explican que la caracterización de este material es su baja capacidad para desarrollar tensiones de tracción, con respecto a una buena resistencia a la compresión. Esto condiciona su estabilidad, que depende de su forma y dimensión, es decir, son estructuras que resisten por su forma más que por la resistencia del material, siempre que 
éste mantenga sus propiedades mecánicas tal como lo afirman estos autores. (Figura 4)

Figura 4. Vista en Planta del cimborrio de la Catedral de San José de Cúcuta.

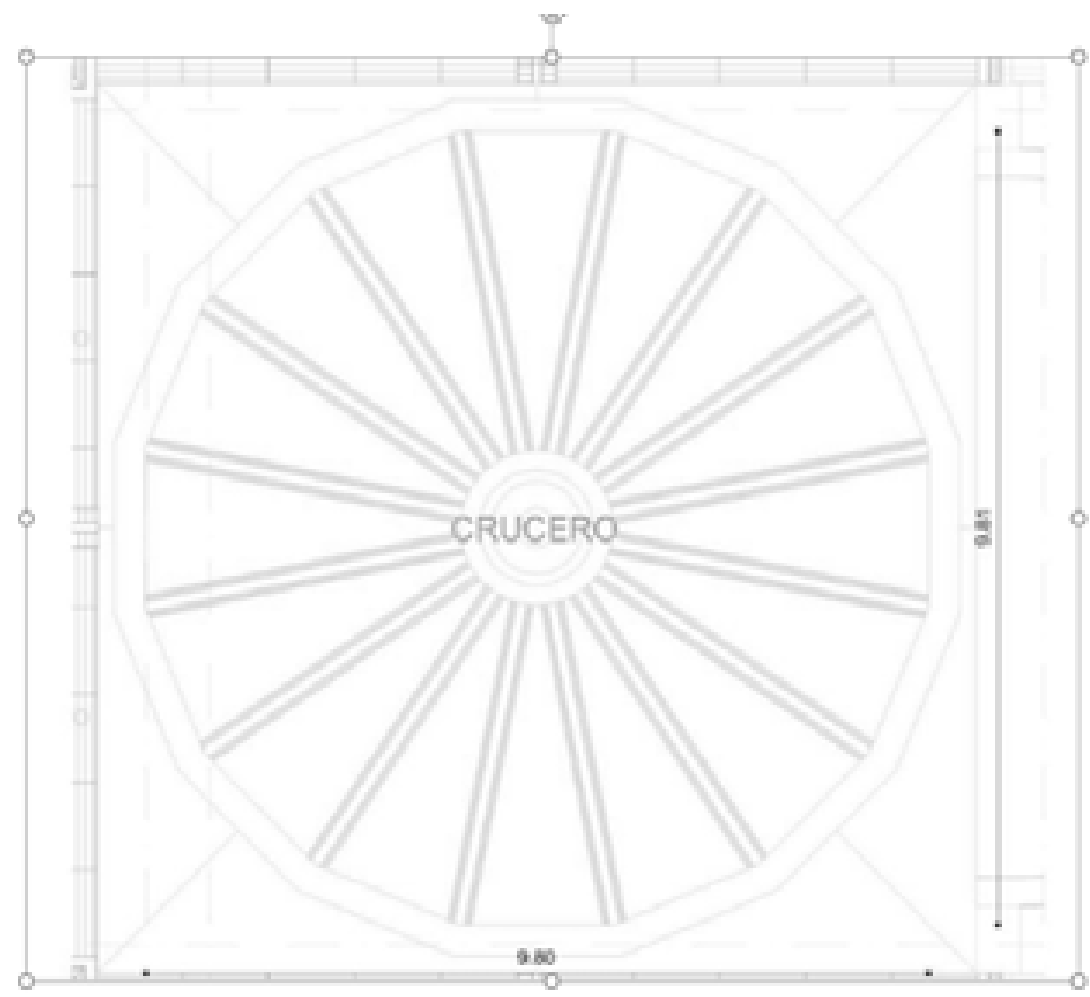

Fuente Propia.

\section{CONCLUSIÓN}

El cimborrio de la Catedral de San José de Cúcuta configura un skyline curvilíneo místico con un valor simbólico, vinculando su significado cosmológico al representar la "bóveda celeste". Aunado a esto, el arte plasmado en el intradós de la cúpula, cumple su misión pedagógica y didáctica, en la que intervienen los haces lumínicos que penetran por el óculo y los vitrales del tambor, al ascender y descender el sol, esto cobra un interesante juego lumínico al interior del crucero.

Como se ha descrito, la cúpula trasciende del tema estético y ornamental para fundamentarse en el simbolismo, esto se explica con la ubicación de la zona presbiteral, en el centro de la iglesia, cambio inspirado en reformas preconciliares cuya intención era la participación de los fieles en la liturgia, de allí lograr una mayor conexión del creyente con la celebración eucarística. En efecto, esta localización del altar en el centro, se ve singularmente en esquemas de forma de cruz latina, tal como se evidencia en la Catedral.

También se destaca la técnica constructiva de la cúpula, en cuanto a sus orígenes, poco precisos, pero con un alto valor cultural, pues la transmisión de la técnica constructiva de la cúpula, alcanzó una alta calidad arquitectónica, precisamente por la participación multicultural y su adquisición paulatina y transmitida a lo largo del tiempo, trabajada con diferentes técnicas. Por lo tanto, se resalta su técnica constructiva elaborada en manufactura de ladrillo, explicando su baja capacidad para desarrollar tensiones de tracción, con respecto a una muy buena resistencia a la compresión. Esto determina su firmeza, que estriba de su forma y dimensión, más que por la resistencia del material y el efecto de levedad que se percibe en el cimborrio. 


\section{REFERENCIAS BIBLIOGRÁFICAS}

Aliberti, L. (2013). Cúpulas clásicas romanas: Geometría y construcción. Actas del Octavo Congreso Nacional de Historia de la Construcción. Madrid, 9-12 de octubre de 2013. Madrid: Instituto Juan de Herrera. Visto en: http://www.sedhc.es/biblioteca/acta.php?id act=10\&id cng=11

Delgado, A., Diaz, Y. \& Vergel, M. (2.018). El paisaje Arquitectónico y sonoro del campanario de la Catedral de San José de Cúcuta. Revista Logos Ciencia \& Tecnología.vol.11 N 1, enero - marzo 2.019 P52-60v

Díaz, Y. (2019). La arquitectura sagrada en San José de Cúcuta (I Parte ): Caso de estudio, Iglesia de Nuestra Señora de la Candelaria. Trabajo investigativo presentado para el escalafón docente. UFPS

Diaz, Y., Delgado rojas, J.A., y Vergel-Ortega, M. Entre las torres de San José: aproximaciones al arte, arquitectura y de la catedral (2020)

Baeza, C. (2014). La ciudad de las cúpulas. Akros, Revista de Patrimonio, n 13, pag 75-82 visto en: file:///C:/Users/Dell/Downloads/Dialnet-LaCiudadDeLasCupulas-4943195.pdf

Huerta, S. (2004). Arcos, bóvedas y cúpulas. Geometría y equilibrio en el cálculo

tradicional de estructuras de fábrica. Instituto Juan de Herrera, Escuela Técnica Superior de Arquitectura. Madrid Visto en: http://oa.upm.es/1136/1/Huerta_2004_Arcos_bovedas_y_cupulas.pdf?

Llonch, J, \& Gurrea, A.( 1996). Hipótesis sobre el origen de las cúpulas nervadas y caladas de la arquitectura hispano-musulmana. Actas del Primer Congreso Nacional de Historia de la Construcción, Madrid, 19-21 septiembre 1996, eds. A. de las Casas, S. Huerta, E. Rabasa, Madrid: I. Juan de Herrera, CEHOPU. Visto en:

Marín, J. (2001). Apuntes en torno al simbolismo de la arquitectura cupulada bizantina. Byzantion Nea Hellás, 19-20, 2000-2001 pág. 142.165. visto en: file:///C:/Users/Dell/ Downloads/37858-1-130387-1-10-20151203\%20(1).pdf

Martínez, A. \& Alonso; A. (2003). Técnicas de diagnóstico estructural en construcciones historicas Análisis de la cúpula de San Miguel de los Reyes (Valencia). LOGGIA №14-15, pag162-171. visto en: file:///C:/Users/Dell/Downloads/3564-11161-1-SM.pdf

Rivas, J. (2008). Las iglesias barrocas de la ciudad de Murcia: consideraciones sobre su significación y arquitectura. IMAFRONTE N. ${ }^{\circ}$ 19-20 -2007-2008. Págs. 395-410. Visto en https://digitum.um.es/ digitum/bitstream/10201/12384/1/19.-\%20Rivas\%20Carmona.pdf

Rosenthal, E. (2011). La catedral de Granada: el altar mayor bajo cúpula. Anuario del Departamento de Historia y Teoría del Arte vol. 23, 2011, pp. 21-30 ISSN. 1130-5517 visto en : https://repositorio.uam.es/ bitstream/handle/10486/7830/43383_2.pdf?sequence $=1$ 